\title{
The role of constitutively activated STAT3 in Bl6 melanoma cells
}

\author{
Chuan He Yang' \\ Meiyun Fan' \\ Andrzej T Slominski' \\ Junming Yue ${ }^{2}$ \\ Lawrence M Pfeffer \\ 'Department of Pathology and \\ Laboratory Medicine, ${ }^{2}$ Department \\ of Physiology, University of \\ Tennessee Health Science Center \\ and the Center for Cancer Research, \\ Memphis, TN, USA
}

This article was published in the following Dove Press journal: International Journal of Interferon, Cytokine and Mediator Research 6 January 2010

Number of times this article has been viewed

\begin{abstract}
Constitutively activated STAT3 is found frequently in a wide variety of human tumors, including melanoma. Moreover, constitutive STAT3 activation actively participates in tumor formation and progression, making STAT3 an attractive target for cancer therapy. We report here that in murine B16 melanoma cells, which have been previously shown to express constitutively active STAT3, the expression of a mutant form of STAT3 with the canonical tyrosine phosphorylation site (residue 705) mutated to phenylanaine has dominant-negative properties (STAT3-DN). STAT3-DN inhibits STAT3 tyrosine phosphorylation and STAT3dependent DNA binding activity. Most importantly, STAT3-DN expression in B16 cells inhibits their invasiveness, as well as their melanogenesis by down-regulation of tyrosinase mRNA and protein expression as well as tyrosinase activity. These results suggest that STAT3 signaling plays a critical role in regulating melanoma behavior, and may represent a druggable target for melanoma therapy.
\end{abstract}

Keywords: STAT3, melanoma, invasion, tyrosinase, melanogenesis

\section{Introduction}

Signal transducers and activators of transcription (STAT) proteins comprise a family of cytoplasmic transcription factors that transmit signals, usually generated by cell surface receptors, to the nucleus where STATs bind to specific DNA promoter sequences and thereby regulate gene expression. Since their discovery as key mediators of cytokine signaling, a total of seven different STAT family members (STAT1, STAT2, STAT3, STAT4, STAT5a, STAT5b, and STAT6) that are encoded in distinct genes have been identified in mammalian cells. The normal physiological functions of individual STAT proteins have been elucidated in studies with STAT knockout mice and/or tissue-specific deletions. ${ }^{1-3}$ These experiments demonstrate that STAT signaling is critical for normal cellular processes such as embryonic development, organogenesis, innate and adaptive immune function, and regulation of cell differentiation, growth, and apoptosis. ${ }^{4}$ Diverse cytokines and growth factors trigger STAT activation. ${ }^{5}$ Under normal physiological conditions STAT proteins are activated temporarily and their activation lasts anywhere from a few minutes to several hours. However, numerous studies have demonstrated constitutive activation of STAT3 in a large number of diverse human tumor cell lines. ${ }^{6}$

Moreover, considerable evidence suggests that constitutive STAT3 activation actively participates in tumor formation and progression, and many studies have contributed to delineation of the mechanisms underlying persistent, oncogenic STAT signaling in tumor cells. ${ }^{7}$ In many cases, tyrosine kinases, essential mediators between extracellular

Correspondence: Lawrence M Pfeffer Cancer Research Building, 19 South Manassas Avenue (Room I54), Memphis, TN 38I63, USA

Fax + I 901 4483910

Email ipfeffer@uthsc.edu 
stimuli and STAT activation, are known to be constitutively active and thereby continuously phosphorylate and activate STAT molecules. ${ }^{8}$ Oncogenic tyrosine kinase signaling can be generated by persistent cytokine and growth factor stimulation, such as interleukin (IL)-6-mediated Janus kinase (JAK) signaling in multiple myeloma and prostate cancer or transforming growth factor (TGF)-mediated epithelial growth factor (EGF) receptor signaling in head and neck cancer. ${ }^{9,10}$ Alternatively, genetic abnormalities of certain cancer types involving the $\mathrm{Bcr}-\mathrm{Abl}$ fusion protein in chronic myelogenous leukemia (CML) represent another mechanism of oncogenic tyrosine kinase activation. ${ }^{11}$ Because uncontrolled activities of many different tyrosine kinases have been long known to participate in oncogenesis, it is not surprising that STATs, which are key mediators of tyrosine kinase signaling, are involved not only in normal physiological processes but also in cancers with aberrantly activated tyrosine kinases. Inhibition of constitutive STAT3 activation in diverse tumor cell lines, by blocking of tyrosine kinase signaling using small molecular inhibitors, has been repeatedly associated with growth suppression and induction of cell death. ${ }^{12,13}$ In contrast, normal cells or tumor cells lacking STAT activation are typically more tolerant to the pharmacological doses used in these experiments. ${ }^{9}$ We examined the effects of directly interfering with STAT signaling by using a dominant-negative STAT3 construct, which we have already established blocks several cytokinemediated biologic events. ${ }^{14-16}$ We propose that targeting the constitutive signaling pathway of STAT3 provides a potential novel strategy for therapeutic intervention in human cancer.

A critical role for STAT3 in malignant transformation was first proposed after initial studies showed that not only is STAT3 constitutively activated during v-Src transformation, ${ }^{17}$ but also that STAT3 signaling is required for oncogenic transformation by $\mathrm{v}$-Src. ${ }^{18,19}$ In addition to $\mathrm{V}$-Src, other transforming tyrosine kinases, such as v-Eyk, v-Ros, v-Fps, Etk/BMX, and Lck, constitutively activate STAT3 in the context of oncogenesis. ${ }^{7}$ Since many different cytokines are known to activate STATs, it is not surprising that constitutive activation of STAT3 is observed downstream of aberrant cytokine signaling derived from either autocrine or paracrine sources. In the context of cytokines, IL-6 signaling through the gp130 receptor subunit is particularly relevant in multiple myeloma and prostate cancer because IL-6-mediated activation of STAT3 has a key role in preventing apoptosis and stimulating growth in cancer cells derived from these tumors. ${ }^{9}$ STAT3 activation is also linked to a number of receptors with intrinsic tyrosine kinase activities that are independent of the cytokine receptor gp130 subunit. ${ }^{7}$
As a point of convergence for numerous oncogenic signaling pathways, STAT3 is constitutively activated at frequency of $50 \%$ to $90 \%$ in diverse human cancers, including melanoma. ${ }^{20}$ Due to the critical role of STAT3 in tumor cell survival, proliferation, angiogenesis, metastasis and immune evasion, targeting STAT3 for therapy assaults cancer on multiple fronts. For example, gene therapy of a mouse model of human melanoma using the STAT3 $\beta$ alternative splice variant of STAT3 with dominant-negative properties suppressed tumor growth of B16 melanoma. ${ }^{21}$ In the present study we transduced B16 melanoma cells with a lentivirus encoding another dominant-negative STAT3 construct, and assayed for STAT3 function. We found that STAT3 activity increases melanoma invasiveness and is required for active melanogenesis by regulating tyrosinase gene expression and enzyme activity.

\section{Materials and methods}

\section{Cell culture}

Murine B16 melanoma cells were cultured as monolayers at $37{ }^{\circ} \mathrm{C}, 5 \% \mathrm{CO}_{2}$, in RPMI-1640 medium with $10 \%$ fetal calf serum (Hyclone, Logan, UT, USA) supplemented with glutamine, penicillin, and streptomycin and subcultured every three days at 10\%-30\% confluency.

\section{Construct design}

The cDNA for the STAT3-DN with a substitution of phenylalanine for the tyrosine at amino acid 705 was digested with SpeI and BamHI, and then inserted into XbaI and BamHI sites of pcFUW-IRES-puro lentiviral vector (Viral Vector Core; University of Tennessee Health Science Center, Memphis, TN, USA) to construct the lentiviral vector pcFUWSTAT3-DN. Lentivirus was produced in 293FT cells by co-transfecting the pcFUW-STAT3-DN with the ViraPower Packaging Mix (Invitrogen, Carlsbad, CA, USA) containing the expression plasmids, pLP/VSVG, pLP1/gag-pol, and pLP2-Rev, which provide the essential elements to package lentivirus. Viral supernatants were collected at 60 hours after transfection and centrifuged ( 15 minutes at $3000 \times \mathrm{g}$ at $4{ }^{\circ} \mathrm{C}$ ) to remove cell debris. Precleared viral preparations were passed through a $0.45-\mu \mathrm{m}$ filter and subjected to ultracentrifugation $\left(17,000 \times \mathrm{g}\right.$ for three hours at $\left.4{ }^{\circ} \mathrm{C}\right)$. The resulting viral pellet was dissolved in phosphate-buffered saline (PBS) and frozen at $-80{ }^{\circ} \mathrm{C}$ until use. Viral titer in 293FT cells was determined by p24 ELISA assays.

\section{Cell proliferation assays}

To determine the effect of STAT3-DN expression on B16 cells, B16 cells were transduced with empty vector pcFUW 
(EV) and pcFUW-stat3-DN lentivirus at a multiplicity of infection of 10, and selected in the presence of puromycin $(1 \mu \mathrm{g} / \mathrm{ml})$. For cell proliferation assays, pools of puromycinselected cells were plated at $1 \times 10^{5}$ cells in 6 -well plates, and at daily intervals cells were harvested by trypsinization and enumerated in a Coulter counter. ${ }^{22}$

\section{Preparation of cell extracts and immunoblot assays}

Cells were gently rinsed twice with ice-cold PBS and total cell lysates prepared by incubation in RIPA buffer (Thermo Scientific, Logan, UT, USA), containing $1 \mathrm{mM} \mathrm{NaF,} 1 \mathrm{mM}$ $\mathrm{Na}_{3} \mathrm{VO}_{4}, 1 \mathrm{mM}$ PMSF, $5 \mu \mathrm{g} / \mathrm{mL}$ soybean trypsin inhibitor, $5 \mu \mathrm{g} / \mathrm{mL}$ leupeptin and $1.75 \mu \mathrm{g} / \mathrm{mL}$ benzamidine at $4{ }^{\circ} \mathrm{C}$ for 30 minutes. Lysates were precleared by centrifugation $(12,000 \times \mathrm{g}, 15$ minutes $)$, separated by sodium dodecyl sulfate polyacrylamide gel electrophoresis (SDS-PAGE), transferred to polyvinylidene difluoride (PVDF) membranes (Millipore) and immunoblotted with $\alpha$ PEP7 anti-tyrosinase, anti-STAT3 and anti-tyrosine phosphorylated STAT3, followed by IRDye $800 \mathrm{CW}$ goat anti-mouse IgG or IRDye 680 goat anti-rabbit IgG (LI-COR Biosciences, Lincoln, NE, USA). Blots were visualized on an Odyssey Infrared Imaging System (LI-COR Biosciences).

\section{Tyrosinase activity}

Tyrosinase activity assay (dihydroxy phenylalanine [DOPA] oxidase) was assayed in cell extracts as described previously using $1 \mathrm{mM}$ L-DOPA as a substrate. ${ }^{23}$ The values are presented as the increase of absorbancy at $475 \mathrm{~nm}$ in time or $\mu$ mols of dopachrome formed per $10^{6}$ cells during one hour incubation. The values represent means from three independent experiments \pm SD performed in duplicate.

\section{Preparation of nuclear proteins, and DNA-binding activity assays}

Cells were washed twice with ice-cold PBS and nuclear proteins were prepared using a Nuclear Extraction Kit (ActiveMotif, Carlsbad, CA, USA). Nuclear extracts (10 $\mu \mathrm{g})$ were incubated with ${ }^{32} \mathrm{P}$-labeled probes for high affinity c-sis inducible element (SIE) in the c-fos gene (5'-AGCTTCATTTCCC GTAATCCCTAAAGCT-3') respectively, and subjected to electrophoretic mobility shift assay (EMSA). ${ }^{24}$ To define the presence of specific STAT proteins in DNA-protein complexes, nuclear extracts were preincubated with a 1:50 dilution of anti-STAT antibodies at $25{ }^{\circ} \mathrm{C}$ for 20 minutes before electrophoretic mobility shift assay (EMSA). Bands were quantified by PhosphorImage autoradiography.

\section{Cell migration assay}

The invasive ability of B16 melanoma cells was assessed by a matrigel-coated filter-invasion assay ${ }^{25}$ In brief, lentivirustransduced B16 melanoma cells were trypsinized, counted, and added in triplicate to the upper well inserts of 24 well plates containing $8-\mu \mathrm{m}$ pore size Transwell inserts (BD Biosciences, Bedford, MA, USA). A total of $1 \times 10^{4}$ cells in RPMI-1640 medium containing 1\% fetal bovine serum (FBS) in a volume of $200 \mu \mathrm{L}$ were added into each insert, and $600 \mu \mathrm{L}$ of RPMI 1640 medium containing 10\% FBS was added to the lower chamber. The cells in the Transwell plates were incubated at $37^{\circ} \mathrm{C}$ for 24 hours. Cells that remained in the inserts were removed with a cotton swab, and cells that migrated through the pores to the underside of the inserts were fixed and stained with Diff-Quick (Baxter Healthcare, McGraw Park, IL, USA). The migrated cells were counted from at least 10 randomly selected microscopic fields, and cell migration is presented as the average number per microscopic field.

\section{Quantitative real-time PCR (qPCR)}

Total RNA was isolated using TRIzol reagent (Invitrogen), and qPCR was performed on an iCyclerIQ (Bio-Rad, Hercules, CA) using iScript One-Step RT-PCR Kit with SYBR Green (Bio-Rad). Reaction parameters were as follows: cDNA synthesis at $50{ }^{\circ} \mathrm{C}$ for $20 \mathrm{~min}$, transcriptase inactivation at $95{ }^{\circ} \mathrm{C}$ for five minutes, PCR cycling at $95{ }^{\circ} \mathrm{C}$ for 10 seconds and $60{ }^{\circ} \mathrm{C}$ for 30 seconds for 40 cycles. The following primers were used for qPCR: $\beta$ actin, 5'-AGAAGGAGATCACTGCCCTG-3' (forward), 5'-CACATCTGCTGGAAGGTGGA-3' (reverse); tyrosinase, 5'-CTCTGGGCTTAGCAGTAGGC-3' (forward), 5'-GCAAGCTGTGGTAGTCGTCT-3' (reverse).

\section{Statistical analysis}

Statistical significance was determined at the $P<0.05$ level by $t$-tests.

\section{Results \\ STAT3-DN inhibits STAT3 tyrosine phosphorylation and the formation of STAT3-dependent DNA binding complexes}

Previous studies established that B16 melanoma cells exhibit low but detectable constitutive activation of STAT3 ${ }^{26}$ The phosphorylation of the $\mathrm{Tyr}^{705}$ residue in STAT3 is critical for the formation of STAT3 dimers and 
DNA binding activity. To determine whether mutation of $\mathrm{Tyr}^{705}$ would inhibit STAT3 function, we transduced B16 cells with a lentivirus encoding a puromycin resistance gene as well as either STAT3-DN or empty vector and pools of puromycin-resistant cells were isolated. The cells were treated with the cytokine IFN $\beta$, which we have shown activates STAT3 in diverse cell types, ${ }^{27}$ lysates prepared and blotted for STAT3 or phospho-STAT3. As shown in Figure 1, IFN induced the phosphorylation of STAT3 in B16 cells transduced with empty vector but not in B16 cells expressing STAT3-DN. Moreover, low constitutive STAT3 activation was evident upon overexposure of the blots in extracts from cells expressing empty vector but not STAT3-DN (data not shown). It is of interest that, although STAT3-DN expression nearly completely ablated basal and IFN-induced STAT3 activation, there was only a $\sim$ twofold increase in the level of STAT3 in STAT3-DN-expressing B16 cells relative to EV-transduced cells as determined by western blotting. To characterize the consequences of STAT3 activation on DNA-binding activity, we prepared nuclear extracts from control and IFN-treated B16 cells and tested for the formation of STAT complexes by gel shift assays with a c-sis inducible element (SIE)-specific oligonucleotide. As shown in Figure 2, IFN induced the formation of STAT1 dimers in STAT3-DN-expressing B16 cells, while in EV transduced cells IFN induced the formation of both STAT3 and STAT1 containing DNA binding complexes. These results demonstrate that expression of STAT3-DN inhibits both STAT3 tyrosine phosphorylation and STAT3-dependent DNA binding activity.

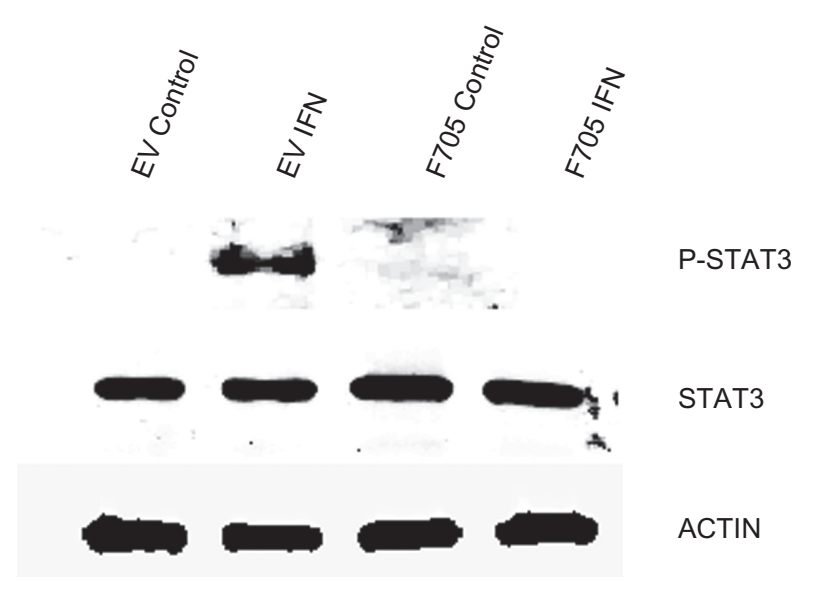

Figure I STAT3-DN inhibits the induction of Tyr-705 phosphorylation in BI6 melanoma cells, Lysates prepared from lentivirus PcFUW and pcFUW-STAT3-DN (F705) transduced BI6 cells after IFN $\beta$ addition (I,000 U/mL for 15 minutes) were resolved by SDS-PAGE, blotted onto PVDF membranes and probed with anti-STAT3, anti-Y705-STAT3 or actin. Results from one of two experiments are shown. Abbreviations: EV, empty vector (in all figures); PVDF, polyvinylidene difluoride.

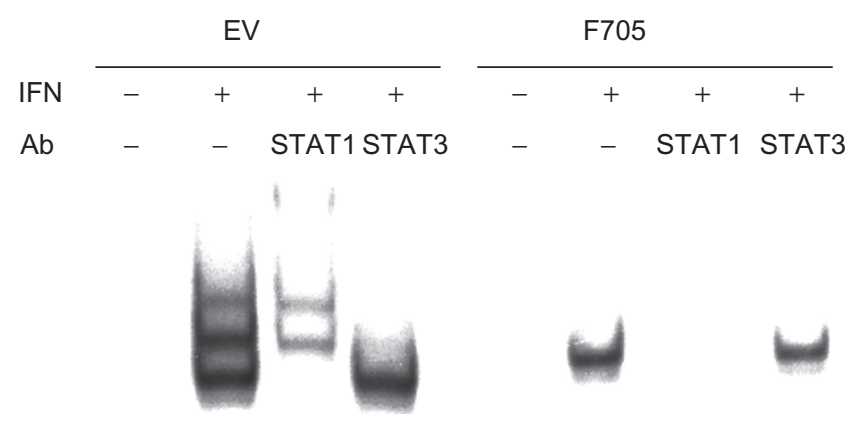

Figure 2 The effects of STAT3-DN on the formation STAT3-dependent DNA-binding complexes. Nuclear extracts from control and IFN $\beta$-treated $(1,000 \mathrm{U} / \mathrm{mL}, 15$ minutes) lentivirus pcFUW and pcFUW-STAT3-DN (F705) transduced BI6 cells were incubated with a $\left[{ }^{32} \mathrm{P}\right]$-labeled SIE probe. To define specific STAT proteins, extracts were preincubated with anti-STATI or anti-STAT3 antibodies prior to EMSA. Results from one of two experiments are shown.

Abbreviations: SIE, c-sis inducible element; EMSA, electrophoretic mobility shift assay.

\section{STAT3-DN does not affect the proliferation of $\mathrm{BI} 6$ cells}

To further characterize the effect of STAT3-DN expression on the behavior of B16 melanoma cells, we next examined the proliferation of EV or STAT3-DN transduced cells. As shown in Figure 3, both EV and STAT3-DN expressing B16 cells grew rapidly, doubling in number every day, and the proliferation curves are almost indistinguishable. Thus, although STAT3-DN expression inhibits both basal and cytokineinduced STAT3 activation, its expression did not affect the

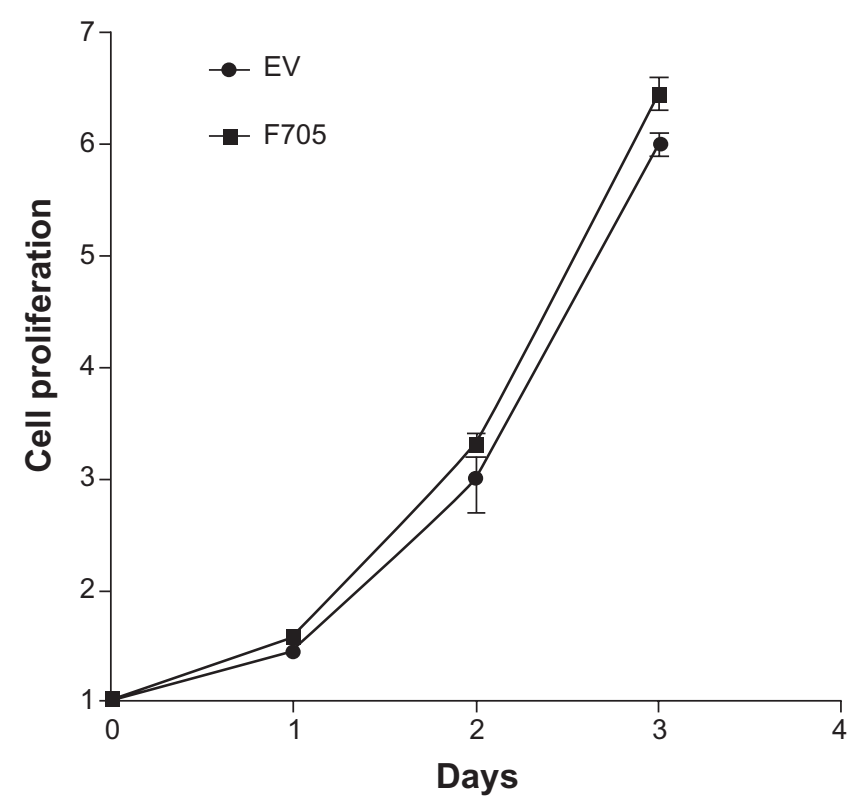

Figure 3 The effect of STAT3-DN on the proliferation of BI 6 cells. EV and STAT3-DN (F705) transduced BI6 melanoma cells were plated into 6-well plates, and at daily intervals cells were harvested by trypsinization and enumerated in a Coulter counter. The data are shown as mean \pm SEM of the number of cells at each time point relative to the number of cells initially plated from three separate experiments $(P=0.89)$. Abbreviation: SEM, standard error of mean. 
proliferation of B16 cells. Moreover, expression of STAT3-DN did not induce any detectable increase cell death when compared to EV transduced B16 cells (data not shown).

\section{STAT3-DN inhibits the invasiveness of $\mathrm{BI} 6$ cells in vitro}

B16 melanoma cells have been used to study tumor cell invasion in vitro and in vivo. To assay whether STAT3 activation affects the invasiveness of B16-melanoma cells in vitro, EV and STAT3-DN transduced cells were subjected to transwell migration assays. In brief, the cells were plated onto matrigel containing transwells and after 24 hours the number of cells that migrated into the lower chamber was quantified. As shown in Figure 4, expression of STAT3-DN reduced tumor invasiveness by $\sim 80 \%$ relative to EV-transduced B16 cells.

\section{STAT3-DN inhibits the melanogenesis of BI 6 through reduction of tyrosinase expression}

B16 cells are highly melanogenic. As the cells reach confluency the media turns dark as well as the cells fill up with melanin-containing granules. As shown in Figure 5, expression of STAT3-DN markedly inhibited the melanin content in cultures. Tyrosinase is a rate-limiting enzyme in melanogenesis. Therefore, we next examined tyrosinase

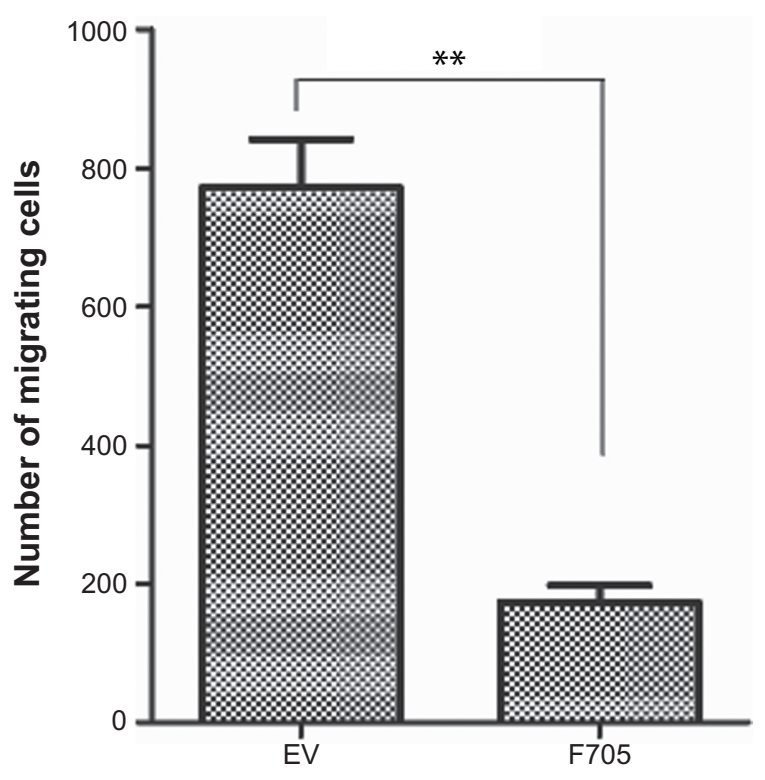

Figure 4 STAT3-DN inhibits the migration of BI6 melanoma cells. BI6 melanoma cells were transduced with lentivirus pcFUW and pcFUW-STAT3-DN (F705) and subjected to subsequent analysis of cell migration by transwell assay. The data are shown as mean \pm SEM of the number of cells migrated in three separate experiments $(P<0.05)$. $* * P=0.01$.

Abbreviation: SEM, standard error of mean.

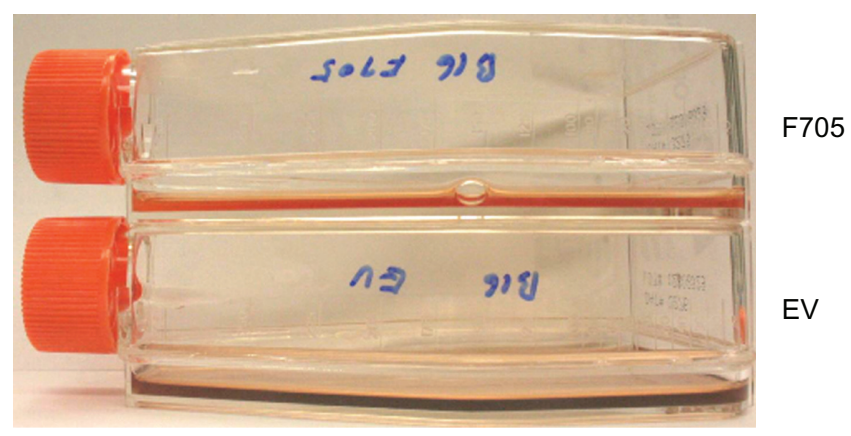

Figure 5 STAT3-DN inhibits melanogenesis of BI6 melanoma cells. BI6 melanoma cells were transduced with lentivirus pcFUW and pcFUW-STAT3-DN (F705) and grown to $70 \%-80 \%$ confluency. The culture flasks were photographed with a digital camera.A representative result from one of three experiments is shown.

gene expression in EV and STAT3-DN-transduced B16 cells. As shown in Figure 6, STAT3-DN expression resulted in a marked reduction in the levels of tyrosinase mRNA, protein, and enzyme activity. Furthermore, by bioinformatic analysis of the mouse tyrosinase gene promoter we identified the presence of a highly conserved STAT binding site ( -14 CAGGGGTTGCTGGAAAAGAAG +7) in the proximal promoter region (from -1000 to +500 around transcription start site) of the mouse tyrosinase gene. Consistent with the western blotting results for STAT3, B16 melanoma transduced with lentiviral STAT3-DN showed a twofold increase in STAT3 mRNA levels relative to EV-transduced cells.

\section{Discussion}

In this study we used the murine B16 melanoma line, which has been previously shown to express constitutively active STAT3. Our results show that inhibition of STAT3 activation expression of a dominant-negative form of STAT3, in which its canonical tyrosine phosphorylation site is mutated to phenylalanine inhibits cancer invasiveness as well as melanogenesis.

STAT3, the transcription factor for acute phase response genes, is activated by a wide variety of cytokines suggesting that it may integrate diverse signals into common transcriptional responses. ${ }^{27-29}$ For example, knockout of the STAT3 gene in mice leads to early embryonic lethality. ${ }^{30}$ Under normal physiological conditions STAT proteins are activated temporarily and their activation lasts anywhere from a few minutes to several hours. However, numerous studies have demonstrated constitutive activation of STAT3 in a large number of diverse human tumor cell lines as evidenced by basal STAT3 tyrosine phosphorylation and DNA binding activity. ${ }^{6,7}$ Elevated STAT3 activity is found frequently in a wide variety of human tumors, including blood malignancies (leukemias, lymphomas, and multiple myeloma), as well as solid tissues (such as melanoma, 

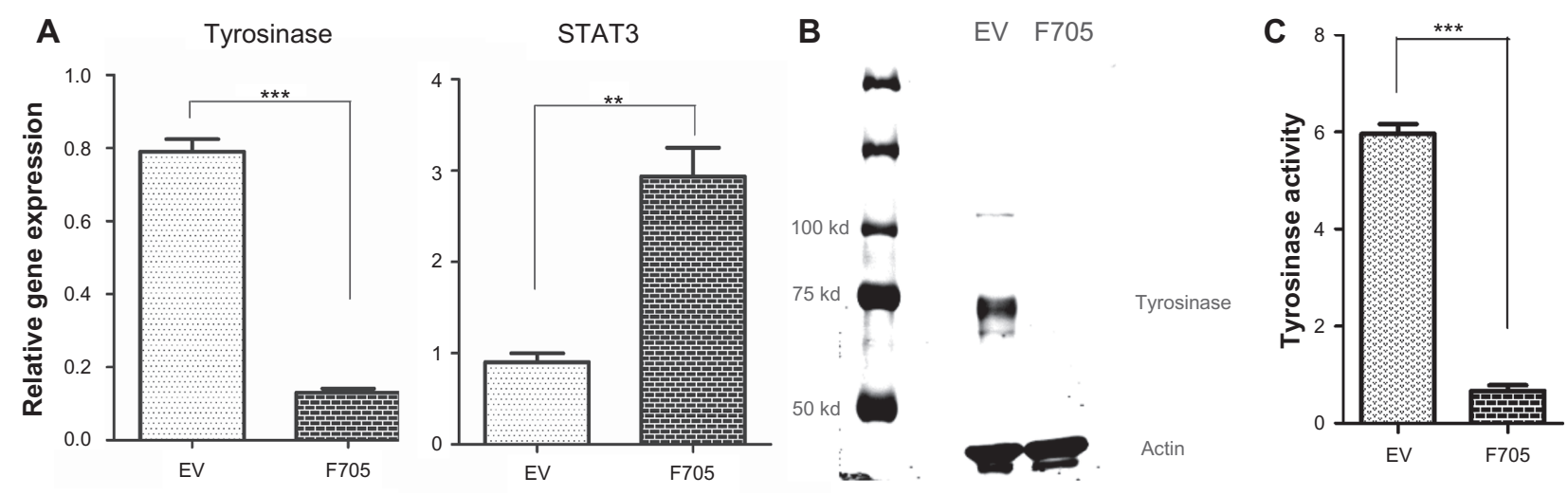

Figure 6 The effect of STAT3-DN on tyrosinase expression and activity in BI6 cells. A) Real-time quantitative PCR for tyrosinase and STAT3 gene expression was performed on RNA prepared from BI6 melanoma cells transduced with lentivirus pcFUW and pcFUW-STAT3-DN (F705). Gene expression was normalized to $\beta$-actin expression in each sample. The data are shown as the mean \pm SEM from three separate experiments $(P<0.05)$. B) Western blot detection of tyrosinase protein using antibodies directed against the $\mathrm{C}$-terminus of mouse tyrosinase. There is marked inhibition of expression of the mature glycosylated form (70 kD range), the precursor form (64 kD) or potential dimers (I20 kD) of tyrosinase in STAT3-DN transduced cells. Protein expression was normalized to $\beta$-actin expression. C) Tyrosinase activity in cell extracts presented as $\mu$ mols per $10^{6}$ cells per hour. Data are mean \pm SD $(n=3)$, *** $<0.0001$

Abbreviations: SEM, standard error of mean; SD, standard deviation.

head and neck, breast, and prostate cancers). Moreover, constitutively activated STAT3 appears to play an important role in tumor formation and progression. ${ }^{7}$

We found that low levels of expression of STAT3-DN blocked STAT3 tyrosine phosphorylation and STAT3dependent DNA binding activity. This is rather remarkable since the levels of expression of the STAT3-DN transgene is at nearly equivalent levels of the endogenous STAT3 expression, as evidenced by western blotting and by real-time PCR analysis of STAT3 mRNA. Moreover, this dominant-negative form of STAT3 markedly inhibited ( $\sim 80 \%$ reduction) the cancer invasiveness in vitro of B16 melanoma cells as determined by transwell migration assays. In addition, STAT3-DN expression also dramatically reduced the melanogenesis of B16 melanoma cells. Malignant melanoma cells commonly retain differentiated characteristics of the melanocytic lineage including active melanogenesis, ${ }^{23,31}$ which may affect behavior of melanoma cells. ${ }^{32}$ The shut-off of melanogenesis in B16 melanoma cells expressing DN-STAT3 appears reflect downregulation of tyrosinase gene expression, which subsequently leads to markedly attenuated tyrosinase protein expression and enzyme activity. Tyrosinase is a rate-limiting enzyme of melanogenesis, which is required for the synthesis of melanin in melanocytes and melanoma cells. ${ }^{33-35} \mathrm{~A}$ role for STAT3 in regulating tyrosinase gene expression is consistent with the presence of a highly conserved STAT3-binding site in the proximal promoter region of the mouse tyrosinase gene. STAT3 integrates the transcriptional signals generated at the cell surface by numerous cytokines and growth factors. However, since the role of STAT3 in regulating melanogenesis is underappreciated, the above findings open an exciting area of investigation on the integration of hormonal or environmental signals into melanogenic activity by STAT3. ${ }^{35}$

STAT3-DN expression appears to selectively affect migration and melanogenesis of B16 melanoma cells. Expression of STAT3-DN had no detectable effect on the proliferation of B16 cells, and did not induce apoptosis. This is in contrast to the findings with another dominant-negative form of STAT3, STAT $3 \beta$, which is an alternative splice form of the STAT3 gene. In this previous study STAT $3 \beta$ expression resulted in a significant inhibition of B16 melanoma cell growth in vitro and in vivo mediated by the induction of tumor cell apoptosis. ${ }^{26}$ Although STAT3 $\beta$ lacks the $\mathrm{C}$-terminal transcriptional activation domain that is conserved in other STAT proteins and is present in STAT3-DN, STAT3 $\beta$ undergoes cytokine-induced tyrosine phosphorylation on tyrosine $705 .^{36,37}$ Since STAT3 $\beta$ is generally considered a dominant negative form of STAT3, therefore it is not surprising that STAT3 $\beta$ expression has a marked affect on the proliferation and apoptosis of B16 melanoma cells when compared to STAT3-DN. Taken together, our results provide further support that STAT3 remains a valid target for developing therapeutics against the various forms of cancer that exhibit constitutively activated STAT3.

\section{Acknowledgments}

Supported by NIH grant CA73753 and AR052190 and DOD grant W81XWH-07-1-0248, and by funds from the Muirhead Chair Endowment at the University of Tennessee Health Science Center. We thank Dr Darren Baker (BiogenIdec) for providing rat IFN $\beta$, and Dr Vincent Hearing (NIH) for providing anti-tyrosinase antibody. The authors report no conflicts of interest in this work. 


\section{References}

1. Akira S. Roles of STAT3 defined by tissue-specific gene targeting. Oncogene. 2000;19:2607-2611.

2. Levy DE. Physiological significance of STAT proteins: investigations through gene disruption in vivo. Cell Mol Life Sci. 1999; 55:1559-1567.

3. Wurster AL, Tanaka T, Grusby MJ. The biology of Stat4 and Stat6. Oncogene. 2000;19:2577-2584.

4. Kotenko SV, Pestka S. Jak-Stat signal transduction pathway through the eyes of cytokine class II receptor complexes. Oncogene. 2000; 19:2557-2565.

5. Ihle JN. The Stat family in cytokine signaling. Curr Opin Cell Biol. 2001;13:211-217.

6. Turkson J, Jove R. STAT proteins: novel molecular targets for cancer drug discovery. Oncogene. 2000;19:6613-6626.

7. Bowman T, Garcia R, Turkson J, Jove R. STATs in oncogenesis. Oncogene. 2000;19:2474-2488.

8. Garcia R, Jove R. Activation of STAT transcription factors in oncogenic tyrosine kinase signaling. J Biomed Sci. 1998;5:79-85.

9. Catlett-Falcone R, Landowski TH, Oshiro MM, et al. Constitutive activation of Stat 3 signaling confers resistance to apoptosis in human U266 myeloma cells. Immunity. 1999;10:105-115.

10. Grandis JR, Drenning SD, Chakraborty A, et al. Requirement of Stat3 but not Stat1 activation for epidermal growth factor receptor- mediated cell growth in vitro. J Clin Invest. 1998;102:1385-1392.

11. Lin TS, Mahajan S, Frank DA. STAT signaling in the pathogenesis and treatment of leukemias. Oncogene. 2000;19:2496-2504.

12. Donato NJ, Wu JY, Zhang L, Kantarjian H, Talpaz M. Down-regulation of interleukin-3/granulocyte-macrophage colony-stimulating factor receptor beta-chain in $\mathrm{BCR}-\mathrm{ABL}(+)$ human leukemic cells: association with loss of cytokine-mediated Stat-5 activation and protection from apoptosis after BCR-ABL inhibition. Blood. 2001;97:2846-2853.

13. Epling-Burnette PK, Liu JH, Catlett-Falcone R, et al. Inhibition of STAT3 signaling leads to apoptosis of leukemic large granular lymphocytes and decreased Mcl-1 expression. J Clin Invest. 2001; 107:351-362.

14. Yang CH, Murti A, Pfeffer LM. STAT3 complements defects in an interferon-resistant cell line: evidence for an essential role for STAT3 in interferon signaling and biological activities. Proc Natl Acad Sci US A. 1998;95:5568-5572.

15. Pfeffer LM, Yang CH, Pfeffer SR, Murti A, McCormack SA, Johnson LR. Inhibition of ornithine decarboxylase induces STAT3 tyrosine phosphorylation and DNA binding in IEC-6 cells. Am J Physiol Cell Physiol. 2000;278:C331-C335.

16. Pfeffer LM, Mullersman JE, Pfeffer SR, Murti A, Shi W, Yang CH. STAT3 as an adapter to couple phosphatidylinositol 3-kinase to the IFNAR1 chain of the type I interferon receptor. Science. 1997;276:1418-1420.

17. Yu CL, Meyer DJ, Campbell GS, et al. Enhanced DNA-binding activity of a Stat3-related protein in cells transformed by the Src oncoprotein. Science. 1995;269:81-83.

18. Bromberg JF, Horvath CM, Besser D, Lathem WW, Darnell JE Jr. Stat3 activation is required for cellular transformation by v-src. Mol Cell Biol. 1998; 18:2553-2558.

19. Cao X, Tay A, Guy GR, Tan YH. Activation and association of Stat3 with Src in v-Src-transformed cell lines. Mol Cell Biol. 1996;16:1595-1603.
20. Xu Q, Briggs J, Park S, et al. Targeting Stat3 blocks both HIF-1 and VEGF expression induced by multiple oncogenic growth signaling pathways. Oncogene. 2005;24:5552-5560.

21. Niu G, Bowman T, Huang M, et al. Roles of activated Src and Stat3 signaling in melanoma tumor cell growth. Oncogene. 2002;21:7001-7010.

22. Eisenkraft BL, Nanus DM, Albino AP, Pfeffer LM. a-Interferon downregulates epidermal growth factor receptors on renal carcinoma cells: Relation to cellular responsiveness to the antiproliferative action of a-interferon. Cancer Res. 1991;51:5881-5887.

23. Slominski A, Moellmann G, Kuklinska E, Bomirski A, Pawelek J. Positive regulation of melanin pigmentation by two key substrates of the melanogenic pathway, L-tyrosine and L-dopa. J Cell Sci. 1988;89(Pt 3):287-296.

24. Yang CH, Murti A, Pfeffer LM. STAT3 complements defects in an interferon-resistant cell line: Evidence for an essential role for STAT3 in interferon signaling and biological activities. Proc Natl Acad Sci US A. 1998;95:5568-5572.

25. Zhang X, Liu Y, Gilcrease MZ, et al. A lymph node metastatic mouse model reveals alterations of metastasis-related gene expression in metastatic human oral carcinoma sublines selected from a poorly metastatic parental cell line. Cancer. 2002;95:1663-1672.

26. Niu G, Heller R, Catlett-Falcone R, et al. Gene therapy with dominantnegative Stat3 suppresses growth of the murine melanoma B16 tumor in vivo. Cancer Res.1999;59:5059-5063.

27. Yang CH, Shi W, Basu L, et al. Direct association of STAT3 with the IFNAR1 signal transducing chain of the type I IFN receptor. $J$ Biol Chem. 1996;271:8057-8061.

28. Akira S, Nishio Y, Inoue M, et al. Molecular cloning of APRF, a novel IFN-stimulated gene factor 3 p91-related transcription factor involved in the gp130-mediated signaling pathway. Cell. 1994;77:63-71.

29. Zhong Z, Wen Z, Darnell JEJ. Stat3: a STAT family member activated by tyrosine phosphorylation in response to epidermal growth factor and interleukin-6. Science. 1994;264:95-98.

30. Takeda K, Noguchi K, Shi W, et al. Targeted disruption of the mouse Stat3 gene leads to early embryonic lethality. Proc Natl Acad Sci USA. 1997;94:3801-3804.

31. Banerjee SS, Harris M. Morphological and immunophenotypic variations in malignant melanoma. Histopathology. 2000; 36:387-402.

32. Slominski A, Paus R, Mihm MC. Inhibition of melanogenesis as an adjuvant strategy in the treatment of melanotic melanomas: selective review and hypothesis. Anticancer Res. 1998;18:3709-3715.

33. Kamaraju AK, Bertolotto C, Chebath J, Revel M. Pax3 down-regulation and shut-off of melanogenesis in melanoma B16/F10.9 by interleukin- 6 receptor signaling. J Biol Chem. 2002;277:15132-15141.

34. Hearing VJ. Biochemical control of melanogenesis and melanosomal organization. J Investig Dermatol Symp Proc. 1999;4:24-28.

35. Slominski A, Tobin DJ, Shibahara S, Wortsman J. Melanin pigmentation in mammalian skin and its hormonal regulation. Physiol Rev. 2004;84:1155-1228.

36. Caldenhoven E, Van Dijk TB, Solari R, et al. STAT3b, a splice variant of transcription factor STAT3, is a dominant negative regulator of transcription. J Biol Chem. 1996;271:13221-13227.

37. Schaefer TS, Sanders LK, Nathans D. Cooperative transcriptional activity of Jun and Stat3b, a short form of Stat3. Proc Natl Acad Sci U S A. 1995;92:9097-9101.

International Journal of Interferon, Cytokine and Mediator Research

Dovepress

\section{Publish your work in this journal}

The International Journal of Interferon, Cytokine and Mediator Research is an international, peer-reviewed, open-access, online journal. The focus of the journal is to publish original research, reports, editorials, reviews and commentaries on all aspects of interferon, cytokine and mediators of inflammation from laboratory science to therapeutic indications and clinical studies. The manuscript management system is completely online and includes a very quick and fair peer-review system, which is all easy to use. Visit http://www.dovepress.com/testimonials.php to read real quotes from published authors. 